\title{
THIRD MOMENT OF YIELD PROBABILITY DISTRIBUTIONS FOR INSTRUMENTS ON SLOVENIAN FINANCIAL MARKETS
}

\author{
Srečko Devjak, Andraž Grum*
}

\begin{abstract}
:
Due to the capital decree legislated by the Bank of Slovenia, Slovenian commercial banks can apply internal models for capital requirements calculation for currency risk and selected market risks (general position risk in line with debt and equity instruments, price change risk for commodities) as an alternative or in combination with standardised methodology. In risk management process banks consider the first and the second moment of a yield probability distribution as portfolio managers seek to achieve the best possible trade-off between risk represented by variance of returns and expected return. In cases when liquidity of instruments on financial markets is low, banks should consider also the third (skewness) and the fourth (kurtosis) moment of a yield probability distribution. All moments define the characteristics of yield probability distribution and therefore affect the risk measure value, being calculated on the basis of yield probability distribution function. The goal of this paper is to calculate the third moment of a yield probability distribution functions for a set of selected assets in financial market in Slovenia and to initiate implementation of a proper risk measure when yield distribution function is not elliptic.
\end{abstract}

Keywords: skewness, risk management, value at risk, bank, yield propability distribution function, risk aversion

JEL Classification: C10, G21

\section{Introduction}

Assume $n$ is the number of time periods of market data for selected financial assets. Let $Y$ be a random variable and let $y_{i}$ be individual values of random variable $Y$. Skewness of a distribution for a population with mean $\mu$ and standard deviation $\sigma$ can be estimated with the following equation (Campbell, Lo, MacKinlay, 1997):

\footnotetext{
*) Srečko Devjak, Bank of Slovenia, Slovenska 35, 1505 Ljubljana (srecko.devjak@bsi.si), Andraž Grum, Abanka Vipa d.d., Slovenska 58, 1517 Ljubljana (andraz.grum@abanka.si).
} 


$$
S=\frac{1}{(n-1) \cdot \sigma^{3}} \cdot \sum_{i=1}^{n}\left(y_{i}-\mu\right)^{3}
$$

For sample estimations it holds (Košmelj, Rovan, 1997):

$$
\begin{gathered}
\mu=\frac{1}{n} \cdot \sum_{i=1}^{n} y_{i} \\
\sigma=\sqrt{\frac{1}{(n-1)} \cdot \sum_{i=1}^{n}\left(y_{i}-\mu\right)^{2}} .
\end{gathered}
$$

Let $f(Y)$ be a probability distribution function of random variable $Y$ and let $a$ be a parameter. The skewness of a symmetric distribution is equal to zero. In this case the following equation applies (Devjak, 1997):

$$
f(\mu-a)=f(\mu+a)
$$

The skewness of a probability distribution is defined with the sign of the numerator in the function $S$ (eq. 1). Negative values for skewness result when $\sum_{i=1}^{n}\left(y_{i}-\mu\right)^{3}<0$ and the distribution is said to be skewed to the left. When the inequality $\sum_{i=1}^{n}\left(y_{i}-\mu\right)^{3}>0$ holds the distribution is skewed to the right and the skewness will be positive. The denominator in the last equality (eq. 3) is used for standardization, making units of measurement irrelevant (Newbold, 1995).

In this paper we will understand a commercial bank as a financial investor. Commercial banks have two possibilities in order to calculate capital charges for market risk they are being exposed to. The first approach is standardised approach, which has to be used by banks in case they do not have an internal model. The standardised approach is based on capital decree legislated by the Bank of Slovenia. Alternatively commercial bank can apply internal model for risk management purposes and it can use several risk measures in order to measure risk. Each risk measure has its strengths and its weaknesses. Consequently, the volume of risk calculated using a specific risk measure will vary among risk measures.

Risk management process in a commercial bank is based on a calculated value of risk measure. Consequently it is very important for a commercial bank to fully understand the interpretation of a selected risk measure. If the volume of risk varies using different risk measures, the decisions upon changes in positions in a portfolio will be different (Devjak, 2004). For the purpose of this article it is important to stress that the usage of specific type of risk measure depends on assumed characteristics of yield probability distributions of assets in trading book portfolio. One of the most frequently used measures of market risk is VaR (value at risk) risk measure ${ }^{1)}$.

Financial investors as banks have to define each securities position in balance sheet as banking book item or as trading book item based on initial intent of secu-

1) More about VaR can be found in Jorion (2001). 
rity acquisition. In risk management process bank should consider yield probability distribution function of each trading book item and consecutively determine appropriate risk measurement approach and measure.

If the skewness of a yield probability distribution function is equal to zero, the distribution is symmetric, what is a general feature of elliptical distributions. The elliptical distribution family includes normal, $t$, and Pareto distributions (Yasuhiro and Toshinao, 2002). It has been proven by Embrechts et al (2002) that VaR is a coherent risk measure (and therefore also sub-additive), when the profit-loss ( $P \& L$ ) distribution is one of the elliptical distribution family mentioned above and has finite variance. The definition of the elliptical distribution family has been explored in Ingersoll (1987).

For this reason, the definition of coherent risk measure will be introduced.

Definition 1. Consider a set V of real-valued random variables. A function $\rho$ : $V \rightarrow R$ is a coherent risk measure if it is (Acerbi, Tasche, 2002):

- monotonous:

$$
X \in V, X \geq 0 \Rightarrow \rho(X) \leq 0
$$

- sub-additive:

$$
X, Y, X+Y \in V \Rightarrow \rho(X+Y) \leq \rho(X)+\rho(Y)
$$

- positively homogeneous:

$$
X \in V, h>0, h X \in V \Rightarrow \rho(h X)=h \rho(X)
$$

- translation invariant:

$$
X \in V, a \in R \Rightarrow \rho(X+a)=\rho(X)-a
$$

Whether VaR is a coherent risk measure on a fixed space of random variables or not, depends only on the joint distribution of the selected market variables. If these variables are elliptically distributed, VaR is a coherent risk measure.

The goal of this paper is to calculate skewness of yield probability distribution functions for selected financial instruments and consequently to determine, whether the difference between skewness of a selected market variable distribution function is significantly different from 0 as it holds for elliptical distributions. For this reason, the sampling theory will be applied. Let $N$ be a set of all financial data of daily yields available ( $n$ data for $Y$ financial instruments). Then, if a standard sample set includes $n$ daily yields, $\left(\begin{array}{l}N \\ n\end{array}\right)$ samples with no repetition can be determined. We would like to test the assumption of skewness for a selected market variable on a set of all market variables, included in the financial analysis. The test will be made not only for the selected time period population data set of $N$ data, but also for the set of all samples of $n$ data. That assumption allows a general conclusion about the skewness of a yield probability distribution function for a selected set of financial instruments in the financial analysis.

To determine the significance level, one sample mean test with 0 as a test value will be applied. Therefore, zero assumption can be defined as $H_{0}: \mu(S)=0$. For setting alternative assumption we shall use two tailed test $H_{1}: \mu(S) \neq 0$ as the distribution can be positively or negatively skewed. 
Let $p$ be a price of financial instrument on the financial market. We will use one sample mean test and if we define $y_{i}=\ln \left(\frac{p_{i}}{p_{i-1}}\right)$, then based on equation 1 the following equation also holds:

$$
S_{i}=\frac{1}{(n-1) \cdot \sigma^{3}} \cdot\left(y_{i}-\mu\right)^{3} \quad \forall i \in\{1,2, \ldots, n\} .
$$

We have to modify the last equation and though obtain equation

$$
S_{i}=n \cdot\left[\frac{1}{(n-1) \cdot \sigma^{3}} \cdot\left(y_{i}-\mu\right)^{3}\right] \quad \forall i \in\{1,2, \ldots, n\}
$$

which is appropriate for one sample test of mean as it holds

$$
\mu(S)=\frac{1}{n} \sum_{i=1}^{n}\left(n \cdot\left[\frac{1}{(n-1) \cdot \sigma^{3}} \cdot\left(y_{i}-\mu\right)^{3}\right]\right)=\frac{1}{(n-1) \cdot \sigma^{3}} \cdot\left(y_{i}-\mu\right)^{3} .
$$

As we have determined $H_{0}: \mu(S)=0$ and $H_{1}: \mu(S) \neq 0$, consequently also follows:

$$
\begin{aligned}
& H_{0}: \mu(S)=\frac{1}{(n-1) \cdot \sigma^{3}} \sum_{i=1}^{n}\left(y_{i}-\mu\right)^{3}=0 \\
& H_{1}: \mu(S)=\frac{1}{(n-1) \cdot \sigma^{3}} \sum_{i=1}^{n}\left(y_{i}-\mu\right)^{3} \neq 0 .
\end{aligned}
$$

\section{Asset Returns Distribution}

One of the most common theoretical models for asset returns is the temporally independently and identically distributed (IDD) normal model, in which returns are assumed to be independent over time, identically distributed over time, and normally distributed (Campbell, Lo, MacKinlay, 1997).

In reality assets returns are not distributed in a way assumed by IDD model. Characteristics of asset returns, their volatility and distribution differ from IDD model as (Poon and Granger, 2002):

- asset returns distribution has fat tails (excess kurtosis),

- asset returns volatility tends to cluster,

- asset returns distribution is asymmetric (skewed) and has mean-reversion tendency and

- volatilities of returns of different financial assets are correlated and therefore not independent.

In this article we focus on skewness of assets return distribution, which is commonly empirically identified in real world financial markets. Andersen et al (2000) show evidence that asset return distributions are usually asymmetric to the right. 


\section{Market Variables in the Financial Analysis}

In the financial analysis several financial instruments from Slovenian capital and money market were included. Chosen instruments are the one that are the most frequent to appear in Slovenian commercial bank trading book portfolio. Government and commercial bonds were omitted from analysis as they are frequently assigned to banking book portfolio as instruments which are hold until maturity and consequently not available for trading. We were considering yield probability distribution functions of treasury bills issued by Ministry of Finance in Slovenia as representatives of money market instruments, selected equities listed on Ljubljana stock exchange (blue chips) and selected currencies in the time period from $4^{\text {th }}$ August 2003 to $4^{\text {th }}$ August 2004. This is in line with quantitative requirement for use of internal models in risk management process as banks have to use one year time series of daily market data. This requirement is stated in a decree of capital adequacy of banks and savings banks legislated by the Bank of Slovenia.

Ministry of Finance issues treasury bills with $1 \mathrm{M}, 3 \mathrm{M}, 6 \mathrm{M}$ and $1 \mathrm{Y}$ maturity, which can be seen as standardised maturities. As treasury bills have different original maturities, we were evaluating skewness of yield probability distributions for all original maturities. In year 2001, OTC - DVP (delivery versus payment) secondary market of Slovenian treasury bills was established. Until then selected commercial banks have been functioning as market makers. Because of the high secondary market turnover, treasury bills are important instruments for balancing liquidity of commercial bank. For each day market makers are obligated to quote bid and ask prices for 16 "life" treasury bills with different original and remaining maturities. The quoted prices on a specific day were chosen to calculate the yield to maturity curve on the money market segment and the process was repeated for each day by applying Nelson-Siegel (1985) model. When the yield to maturity curve was estimated we used the interpolation and extrapolation method to evaluate the appropriate prices of treasury bills for standardised maturities for each day. Let $p$ be (discounted) price of a treasury bill. Then daily price change $y_{i}$ of a predefined standardised maturity money market instrument can be calculated as $y_{i}=\ln \left(\frac{p_{i}}{p_{i-1}}\right)$.

From capital market several equities from Ljubljana stock exchange were included in the analysis. Chosen equities have the greatest turnover and the greatest weight in SBI20 stock exchange index. Those were equities of Slovenian blue chips Krka (KRKG), Mercator (MELR) and Petrol (PETG). The last two are the biggest Slovenian companies in terms of total revenues. To satisfactory replicate trading book positions of commercial banks stocks of selected investment company were included in analysis. Investment companies are a result of Slovenian voucher privatization and are very popular between investors because they offer portfolio diversification with relatively low transaction cost. Their investment policy is very similar to the policy of exchange-traded funds. NFD investment company (NF1N) is the biggest closed mutual fund on Slovenian capital market in terms of net asset value and also the most liquid one.

Among foreign currencies, banks in Slovenia have most of their positions denominated in EUR, USD, GBP, CHF and HRK currencies. In the composition of currency portfolio EUR fraction is dominant. Therefore EUR/SIT exchange rate as 
currency risk factor was included in financial analysis. There are several sources of data available for EUR/SIT exchange rate. To calculate skewness of yield probability distribution function for EUR/SIT exchange rate, middle exchange rates of the Bank of Slovenia were used instead of Reuters data. The decision is supported with covariance calculation between two different time series of data. Let BSerEUR be middle Bank of Slovenia exchange rate and let REUTerEUR be Reuters EUR/SIT exchange rate. To understand the covariance of two exchange rates we shall apply the dependence test with assumptions $H_{0}: \rho_{\text {BSerEUR.REUTerEUR }}=0$ and $H_{1}: \rho_{\text {BSerEUR.REUTerEUR }}>0$. For this purpose we used exchange rates for 250 trading days before the ERM2 entrance date. The calculated bivariate correlation coefficient is high $\rho=0,997$ and statistically significant with $\rho=0,000$.

\section{One Sample Mean Test}

Using assumptions $H_{0}: \mu(S)=0$ and $H_{1}: \mu(S) \neq 0$ we have calculated test value and significance level for each included financial instrument. Assumption $H_{0}: \mu(S)=0$ can only be rejected for EUR/SIT exchange rate with a negligible risk of $\rho=0,000$. Therefore, all distribution functions of yields of financial instruments in the analysis are symmetric and therefore elliptical, except EUR/SIT exchange rate yield, which is not symmetric as $H_{1}: \mu(S) \neq 0$ holds with $\rho=0,000$.

Table 1

Test Values and Significance Levels for Yields of Financial Instruments in the Analyses

One-Sample Test

\begin{tabular}{|c|c|c|c|c|c|c|}
\hline & \multicolumn{6}{|c|}{ Test Value $=0$} \\
\hline & \multirow[b]{2}{*}{$\mathrm{t}$} & \multirow[b]{2}{*}{ df } & \multirow[b]{2}{*}{ Sig. (2-tailed) } & \multirow{2}{*}{$\begin{array}{c}\text { Mean } \\
\text { Difference }\end{array}$} & \multicolumn{2}{|c|}{$\begin{array}{l}95 \% \text { Confidence } \\
\text { Interval of the } \\
\text { Difference }\end{array}$} \\
\hline & & & & & Lower & Upper \\
\hline$\overline{\mathrm{KRKG}}$ &,- 254 & 264 & ,799 &,- 13312241 & $-1,16310$ & ,8968551 \\
\hline MELR &,- 098 & 264 & ,922 &,- 03844483 &,- 808223 & ,7313335 \\
\hline PETG & ,273 & 264 & ,785 & ,09816057 &,- 609704 & ,8060247 \\
\hline NF1N & ,185 & 264 & ,854 & 06063105 &,- 585491 & ,7067527 \\
\hline EUR & $-165,695$ & 264 & ,000 &,- 01143871 &,- 011575 &,- 011303 \\
\hline
\end{tabular}

Source: own calculation.

Table 1 shows that EUR/SIT yield distribution function is not elliptical. Therefore, we are going to calculate skewness for the distribution to find out, whether we are dealing with positive or negative skewness. 


\section{Table 2}

The Value of Skewness Statistic for Market Variables in the Analysis

\section{Descriptive Statistics}

\begin{tabular}{|l|r|r|r|}
\hline \multirow{2}{*}{} & \multicolumn{1}{|c|}{$\mathrm{N}$} & \multicolumn{2}{|c|}{ Skewness } \\
\cline { 2 - 4 } & Statistic & \multicolumn{1}{|c|}{ Statistic } & Std. Error \\
\hline KRKG & 265 &,- 134 &, 150 \\
MELR & 265 &, 017 &, 150 \\
PETG & 265 &, 211 &, 150 \\
NF1N & 265 &, 142 &, 150 \\
EUR & 265 & 1,340 &, 150 \\
Valid N (listwise) & 265 & & \\
\hline
\end{tabular}

Source: own calculation.

Table 2 indicates EUR/SIT exchange rate daily distribution is skewed to the right as the skewness statistic is positive and therefore $\sum_{i=1}^{n}\left(y_{i}-\mu\right)^{3}>0$. Detected skewness can be seen from Figure 2.

Figure 1

Frequency Distribution Function of KRKG Daily Yields with Adjusted Normal Curve

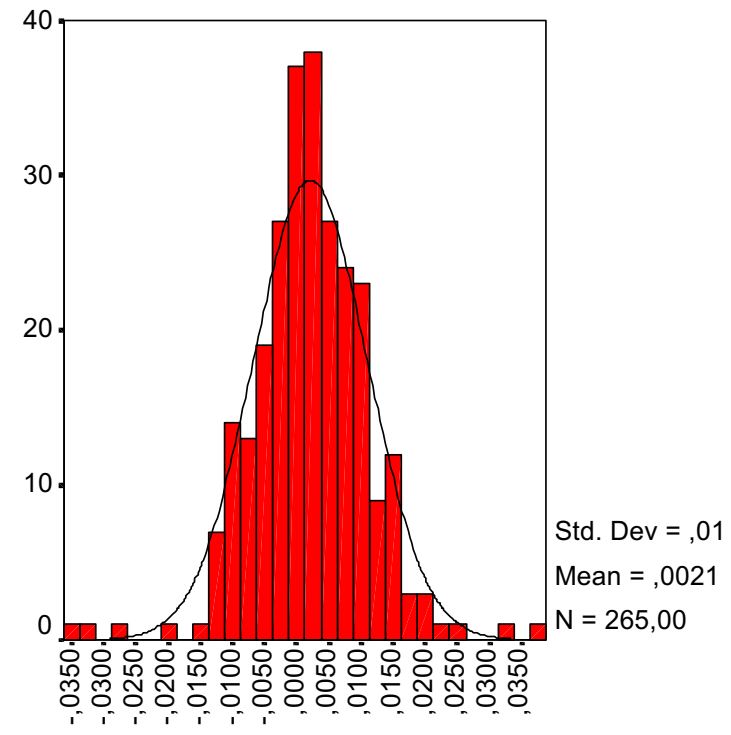

KRKG

Source: own calculation. 
Figure 1 and Table 2 show that yield distribution of Krka is negatively skewed, but the test statistics is not significant. Although inequality

$$
S_{K R K G}=\frac{1}{(n-1) \cdot \sigma^{3}} \sum_{i=1}^{n}\left(y_{i}-\mu\right)^{3}<0 \Leftarrow \sum_{i=1}^{n}\left(y_{i}-\mu\right)^{3}<0
$$

holds, assumption $H_{0}: \mu(S)=0$ cannot be rejected.

Figure 2

Frequency Distribution Function of EUR/SIT Daily Yields with Adjusted Normal Curve

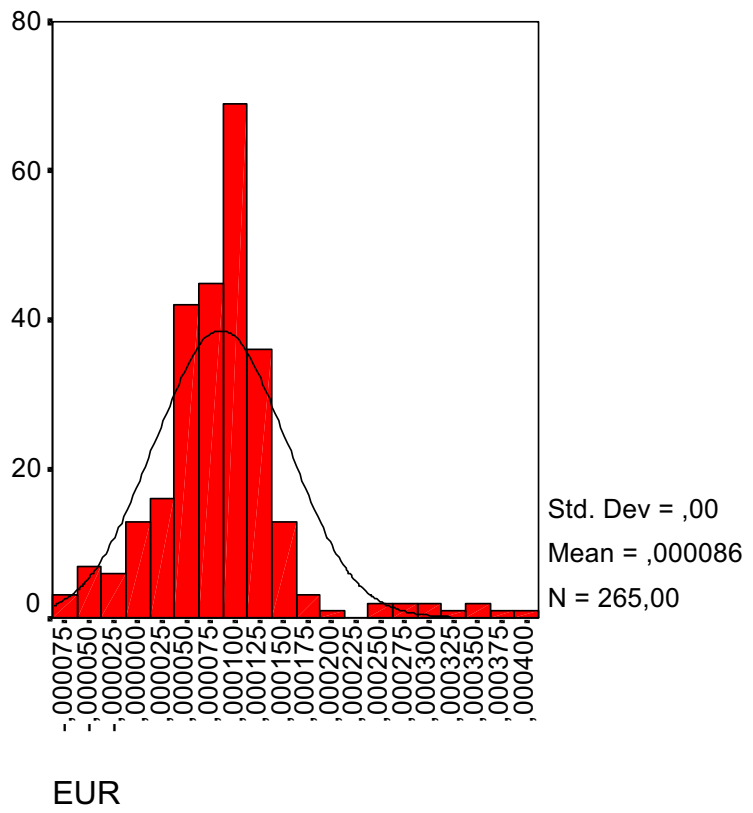

Source: own calculation.

We are going to apply one sample mean test also for selected money market instruments, to test the assumptions $H_{0}: \mu(S)=0$ and $H_{1}: \mu(S) \neq 0$. 
Table 3

Test Values and Significance Levels for Yields of Money Market Instruments

One-Sample Test

\begin{tabular}{|c|c|c|c|c|c|c|}
\hline & \multicolumn{6}{|c|}{ Test Value $=0$} \\
\hline & \multirow[b]{2}{*}{$\mathrm{t}$} & \multirow[b]{2}{*}{$d f$} & \multirow[b]{2}{*}{ Sig. (2-tailed) } & \multirow{2}{*}{$\begin{array}{c}\text { Mean } \\
\text { Difference }\end{array}$} & \multicolumn{2}{|c|}{$\begin{array}{l}95 \% \text { Confidence } \\
\text { Interval of the } \\
\text { Difference }\end{array}$} \\
\hline & & & & & Lower & Upper \\
\hline $1 \mathrm{M}$ & $-2,390$ & 249 & ,018 &,- 00117351 &,- 0021407 &,- 0002063 \\
\hline $3 \mathrm{M}$ & $-2,666$ & 249 & ,008 &,- 00119062 &,- 0020702 &,- 0003110 \\
\hline $6 \mathrm{M}$ & $-2,363$ & 249 & ,019 &,- 00120100 &,- 0022021 &,- 0001999 \\
\hline $12 \mathrm{M}$ & $-1,971$ & 249 & ,050 &,- 00121161 &,- 0024223 &,- 0000009 \\
\hline
\end{tabular}

Source: own calculation.

Table 3 indicates, $H_{0}: \mu(S)=0$ can be rejected for all money market instruments as in all cases critical probability level is $\rho \leq 0,05$. Therefore, all yield distribution functions for money market instruments are not symmetric and therefore also not elliptic. In order to define skewness of a distribution, the third moment should be calculated. On the basis of sign of a function $S$, negative or positive skewness will be defined.

Table 4

The Value of Skewness Statistic Market Variables in the Analysis

Descriptive Statistics

\begin{tabular}{|l|r|r|r|}
\hline \multirow{2}{*}{} & \multicolumn{1}{|c|}{$\mathrm{N}$} & \multicolumn{2}{|c|}{ Skewness } \\
\cline { 2 - 4 } & Statistic & \multicolumn{1}{|c|}{ Statistic } & Std. Error \\
\hline $1 \mathrm{M}$ & 250 &,- 357 &, 154 \\
$3 \mathrm{M}$ & 250 &, 658 &, 154 \\
$6 \mathrm{M}$ & 250 &, 538 &, 154 \\
$12 \mathrm{M}$ & 250 &, 179 &, 154 \\
Valid N (listwise) & 250 & & \\
\hline
\end{tabular}

Source: own calculation.

Daily yield probability distribution function for 1M T-bills is negatively skewed as in equation $\sum_{i=1}^{n}\left(y_{i}-\mu\right)^{3}=-0.357<0$ holds. One of the reasons for detected negative skewness of yield distribution function for 1 month T-bills can be found in the relative importance of transaction cost on the short term segment of the yield curve. Short term T-bills are more sensitive to transaction cost, as market makers can achieve desired yield to maturity on investment after the cost only if price of T-bills 
drops more than proportionally, leading to extreme negative daily yields. All other probability distribution functions are positively skewed as $\sum_{i=1}^{n}\left(y_{i}-\mu\right)^{3}>0$.

\section{Conclusion}

The third moment of a probability distribution function is very important when applying internal risk management models in commercial banks operating in small financial markets. Positive skewness is common case for financial instruments in financial markets, while negative skewness is exceptional. In this financial analysis it has been proven negative skewness for KRKG equities and for T-bills with $1 \mathrm{M}$ standardised original maturity. For all other instruments in the financial analyses, positive skewness has been proven. Based on results in financial analyses, skewness has been proven to be statisticly different from 0 in case of EUR/SIT exchange rate and in case of all money market instruments. For portfolios of financial instruments with skewness being different from 0 , VaR as risk measure is not a coherent risk measure.

\section{References}

Andersen T. G., Bollerslev T., Diebold F. X, Ebens H. (2000), "The Distribution of Stock Return Volatility". National Bureau of Economic Research, Working Paper No. 7933.

Acrebi C., Tasche D. (2002), Expected Shortfall: a Natural Coherent Alternative to Value at Risk. Economic Notes, (2), pp. 379-388.

Campbell J. Y., Lo A. W., MacKinlay C. A. (1997), The Econometrics of Financial Markets. Princeton: Princeton University Press.

Devjak S. (2004), Optimisation of the Securities Portfolio as a Part of the Risk Management Process. Faculty of Economics. Journal of Contemporary Management Issues, June 2004 (1), pp. 81-91. Split: Management.

(1997), Matematične metode v managementu. Statistika. Koper: Visoka šola za management Koper.

Embrechts P., McNeil A., Straumann D. (2002), "Correlation and Dependency in Risk Management: Properties and Pitfalls". University of Haifa, Technical Report N 02-04.

Ingersoll, J. E., Jr. (1987), Theory of Financial Decision Making. Rowman \& Littlefield Publishers.

Jorion, P. (2001), Value at Risk: The New Benchmark for Controlling Market Risk, 2nd Ed. New York: McGraw-Hill.

Košmelj, B., Rovan, J. (1997), Statistično Sklepanje. Ljubljana: Ekonomska fakulteta.

Nelson, Ch. R., Siegel, A. F. (1985), "Parsimonious Modelling of Yield Curves for U.S. Treasury Bills". Cambridge: National Bureau of Economic Research, Working Paper No. 1594.

Newbold, P. (1995), Statistics for Business and Economics, 4th Ed. Englewood Cliffs, New Jersey: Prentice-Hall International.

Poon Ser-lluang, Granger, C. (2002), Forecasting Volatility in Financial Markets: A Review. Journal of Economic Literature, 41, (2), pp. 478-539.

Yamai Yasuhiro, Yoshiba Toshinao: "On the Validity of Value at Risk: Comparative Analyses with Expected Shortfall”. Bank of Japan: Monetary and Economics Studies, 2002 (1), pp. 57-86. 